\title{
Local level inequalities in the use of hospital-based maternal delivery in rural South Africa
}

\author{
Sheetal Prakash Silal ${ }^{1 *}$, Loveday Penn-Kekana², Till Bärnighausen ${ }^{3,4}$ and Helen Schneider ${ }^{5}$
}

\begin{abstract}
Background: There is global concern with geographical and socio-economic inequalities in access to and use of maternal delivery services. Little is known, however, on how local-level socio-economic inequalities are related to the uptake of needed maternal health care. We conducted a study of relative socio-economic inequalities in use of hospital-based maternal delivery services within two rural sub-districts of South Africa.

Methods: We used both population-based surveillance and facility-based clinical record data to examine differences in the relative distribution of socio-economic status (SES), using a household assets index to measure wealth, among those needing maternal delivery services and those using them in the Bushbuckridge sub-district, Mpumalanga, and Hlabisa sub-district, Kwa-Zulu Natal. We compared the SES distributions in households with a birth in the previous year with the household SES distributions of representative samples of women who had delivered in hospitals in these two sub-districts.
\end{abstract}

Results: In both sub-districts, women in the lowest SES quintile were significantly under-represented in the hospital user population, relative to need for delivery services ( $8 \%$ in user population vs $21 \%$ in population in need; $p<0.001$ in each sub-district). Exit interviews provided additional evidence on potential barriers to access, in particular the affordability constraints associated with hospital delivery.

Conclusions: The findings highlight the need for alternative strategies to make maternal delivery services accessible to the poorest women within overall poor communities and, in doing so, decrease socioeconomic inequalities in utilisation of maternal delivery services.

Keywords: Maternal health, Socio-economic inequalities, Access, Maternal delivery services

\section{Background}

Internationally, there is increased recognition that high levels of intra-country disparities in maternal health outcomes are as important to tackle as international disparities if the 2015 Millennium Development Goal of a reduction in maternal mortality is to be achieved. The ongoing discussions on the goal for ending preventable maternal mortality and the post-2015 development agenda highlight the need for ensuring that care is provided universally but also to those who need it most. Using data from the South Africa Demographic and Health Surveys (DHS) and Multiple Indicator Cluster Surveys, national level inequalities in access to maternal health services have been documented along geographical (regional,

\footnotetext{
* Correspondence: Sheetal.Silal@uct.ac.za

${ }^{1}$ Department of Statistical Sciences, University of Cape Town, Cape Town, South Africa

Full list of author information is available at the end of the article
}

urban-rural) socio-economic and, at times, ethnic or racial lines $[1,2]$. At the national level, inequalities are most pronounced in access to skilled birth attendance and comprehensive emergency obstetric care (CEOC) $[3,4]$ and considerably wider than inequalities in access to antenatal care (ANC) and childhood immunisation [5].

South Africa's Maternal Mortality Ratio (MMR) at 310 per 100000 live births is high for a middle-income country. While the devastating HIV/AIDS epidemic partly accounts for poor maternal outcomes, South Africa's apartheid past and high levels of inequality are also seen to be contributing factors [6]. Although 2003 DHS data showed that on average $91 \%$ of women delivered with skilled attendance, there were significant urbanrural, racial and socio-economic inequalities in this parameter. In rural areas, skilled attendance at delivery was $85 \%$ compared to $94 \%$ in urban areas; delivery in a hospital was 
$67 \%$ in rural areas compared to $80 \%$ in urban areas [7]. Inequalities in socio-economic status (SES) have a similar profile: $65 \%$ of the women in the poorest quintile delivering in hospitals compared to $89 \%$ of women in the SEShighest quintile. Wabiri et al. [8] in an analysis of national household survey data, concluded that while inequalities in SES in many indicators of access to maternal healthcare were small, women in the poorest quartile attended ANC later compared to relatively wealthier women (though attendance itself was high), and had lower skilled attendance rates. While it is known that nationally, maternal health services are not equally utilised, what is not known is the degree of SES inequality in maternal care service utilization at the district or sub-district level.

There has been a strong commitment from national government to tackle maternal mortality. Initiatives have included prioritising pregnant women for antiretroviral (ARV) treatment, appointment of district maternal and child health $(\mathrm{MCH})$ teams, training community health workers in $\mathrm{MCH}$, and plans to increase the availability of waiting homes and obstetric ambulances. In many rural areas, women are encouraged to deliver in hospitals or in health centres close to hospitals where there is ready access to Caesarean section, blood transfusions and other elements of comprehensive emergency obstetric care.

In this study, we thus examine for the first time socioeconomic inequalities in utilisation of maternal delivery in public-sector hospitals in two rural sub-districts of South Africa, where established Health and Demographic Surveillance System (HDSS) sites provide an opportunity for such a study. Initiatives to reduce maternal mortality will be strengthened by a better understanding of socioeconomic gradients in the use of maternal health care faced by poorer women in rural areas. The district/ sub-district level is important as it is the most decentralised managerial level of the health system where an appropriate fit between health care need and access can be ensured.

This analysis of maternal delivery forms one part of a larger study (REACH: Researching Equity in ACcess to Healthcare) funded by the Canadian International Development Research Centre, which explores inequalities in access and use of health care in South Africa of three health interventions: maternal health deliveries, tuberculosis treatment and anti-retroviral therapy for HIV.

\section{Methods}

We conducted an analysis of inequality in utilization of hospital-based maternal delivery services in the Bushbuckridge and Hlabisa health sub-districts of Mpumalanga and Kwa-Zulu Natal Provinces, respectively. These two sub-districts were chosen because they both have HDSS providing population-level data on SES, births, and location of delivery. In the analysis, the SES of households with a birth in a woman 18 years or older in the previous year, obtained from HDSS data, was compared with the household SES, obtained from a representative sample of women, 18 years or older, who had delivered in hospitals in the two sub-districts. In 2009, 90.4\% and $79.4 \%$ of maternal deliveries in Bushbuckridge and Hlabisa, respectively, took place in the formal health system (i.e. with skilled attendance). Of these, the vast majority (95\% in Bushbuckridge and 92\% in Hlabisa) occurred in hospital facilities [9]; hence the decision to conduct interviews at hospitals. Pregnancies that terminated in abortions or where the outcome was unknown were not included in the analysis.

\section{Population level data}

The Agincourt HDSS (AHDSS) consists of an annual census of approximately 107500 people (as of May 2013) in an area of Bushbuckridge [10]. The following data were extracted from the AHDSS for the year 2007 from the 10,511 households with complete socio-economic data: number of pregnancies and their outcomes, maternal age and education, household characteristics, namely type of material used to construct the house walls and roof, access to water, toilet type, fuel used to cook, and ownership of assets such as a TV, fridge, stove, radio, landline telephone, vehicle, bicycle, and livestock. The 1,527 households with a woman over 18 years of age who had delivered in the preceding year were defined as the households needing maternal health services. The Africa Centre Demographic Information System (ACDIS) collects similar data on approximately 85,000 people in an area of Hlabisa [11]. Data from this database were extracted for 2009 on 8,448 households with complete socio-economic data and the subset of 1,491 households with a woman over 18 years of age who had delivered in the preceding year. Additional data on ownership of the following assets were available from this census: bed-nets, bed, blockmaker, car battery, hot plate, kettle, gas cooker, kombi (vehicle), sink, motorcycle, primus stove, sofa, sewing machine, table and chairs, DVD player and wheelbarrow. Household characteristics and assets from both datasets were used to estimate an SES measure for each household in the two populations.

\section{SES index}

We use Multiple Correspondence Analysis (MCA) to create an SES index. MCA, an extension of Correspondence Analysis, is used to measure the relationships between several categorical variables. MCA aims to decrease high dimensional data space through finding dimensions that capture the largest amount of information common to all the variables [12]. The SES index was computed separately for each sub-district using the HDSS population data on access to basic services (water, electricity, sanitation), type 
of house, and the household assets listed above. We only use the index formed by the first dimension identified in $\mathrm{MCA}$, as this index already captures a very large proportion of the common information between the socioeconomic variables $(79 \%$ and $74 \%$ in Bushbuckridge and Hlabisa, respectively). Once the continuous SES index was constructed for each sub-district, households were ranked by SES and grouped into quintiles ranging from lowest to highest SES. We use this relative measure of socioeconomic status, SES quintiles, to allow comparison of SES gradients across the two sub-districts included in our analyses. The absolute values of the continuous indices cannot be directly compared because their meanings differ in the communities.

\section{Sub-district level user data}

We conducted patient exit interview surveys in women over 18 years of age delivering in one of the three hospitals in the two sub-districts (two in Bushbuckridge and one in Hlabisa) during the study period. Based on a Chi-squared Goodness-of-Fit test, we estimated that a sample of 300 women per sub-district would be required to detect SES differences with $80 \%$ power. In Bushbuckridge the sample was distributed proportional to the number of deliveries in each of the two hospitals. Respondents were recruited systematically at the time of discharge from the post-natal ward until the required sample size was achieved in each facility. Trained interviewers carried out the exit interviews in the local language of the respondent, collecting socio-economic data, as well as additional access variables related to the geographic accessibility, financial affordability, and cultural acceptability of hospital delivery services. During the course of the survey, a structured quality inventory on health systems inputs, processes and outputs was also completed in each hospital to measure the hospital capacity for comprehensive emergency obstetric care.

Data were collected over a period of 15 months, from June 2008 through September 2009. Ethical clearance for this study was obtained from the Universities of Cape Town, Witwatersrand and KwaZulu Natal, and provincial and local Departments of Health authorized the study. Written, informed consent was obtained from each participant in the exit interviews.

\section{Comparing the SES distributions of people needing and people using maternal delivery services}

The SES distribution of the population in each subdistrict, categorised into quintiles, was used to compare the SES distributions of the women needing and using maternal delivery services. We determined first the proportion of women in each quintile in need of maternal delivery services and then the proportion of women in each quintile who actually used these services. In this way these SES distributions are directly comparable. In order to test for trends and associations between those needing maternal delivery services and those who used these services, the Partitions of Pearson's Chi-squared test for ordered columns, a contingency table analysis of ordered categorical variables (such as quintiles), was conducted [13].

\section{Results}

The maternal health and service profile of the two subdistricts is summarised in Table 1. While both sites are considered poor rural areas, they nevertheless have different degrees of absolute disadvantage. Hlabisa sub-district is a more remote rural area than Bushbuckridge, and households have less access to piped water, and higher HIV prevalence and MMR than in Bushbuckridge. All three hospitals surveyed for this study were able to perform the signal functions of comprehensive emergency obstetric care (parenteral antibiotics, oxytocic drugs and anticonvulsants, facilities for the manual removal of placenta and retained products, assisted vaginal delivery and caesarian sections, and blood transfusion) [14]. In addition, the regional hospital in Bushbuckridge had a specialist obstetrician able to deal with complex obstetric emergencies.

The vast majority of facility births in the two subdistricts occurred in the hospitals $(94.6 \%$ in Bushbuckridge and $91.0 \%$ in Hlabisa), with the balance of births at a facility taking place in community health centres and in local clinics.

Figures 1 and 2 present the findings of the utilisation analysis in the two sub-districts. The population SES distribution was decomposed into even quintiles ranked from lowest to highest, and compared with the SES of households needing maternal health services ('Need') and with the household SES of those delivering in hospitals ('Use'). A total of 599 exit interviews - 299 in Bushbuckridge and 300 in Hlabisa - provided the data on the SES profile of the hospital user population.

In both sub-districts, the SES distribution of those needing maternal delivery services was not vastly different to that of the population, with the exception of a lower proportion of pregnancies among those women from households in the highest quintile. However, the SES distribution of the hospital user group showed distinct "pro-rich" patterns. In Bushbuckridge, users in the highest two quintiles comprised nearly $60 \%$ of all users. Further, while $41 \%$ of those needing maternal delivery services belonged to the lowest two quintiles, only $20 \%$ of users in our sample were from these two quintiles. The Partitions of Pearson's Chi-squared test shows highly significant overall differences between need and use (p-value $<0.001$ ) and further significant differences in location in the SES distribution between need and use (p-value $<0.001$ ). 
Table 1 Socio-demographic, maternal health and service profile of study sub-districts

\begin{tabular}{|c|c|c|c|c|}
\hline & \multicolumn{2}{|c|}{ Bushbuckridge } & Hlabisa & Source \\
\hline Population (2007) & \multicolumn{2}{|l|}{509,970} & 150,557 & [15] \\
\hline Household access to piped water (2008/9) & \multicolumn{2}{|l|}{$90.0 \%$} & $58.0 \%$ & {$[16]$} \\
\hline Percentage of births with skilled attendant (Whole district) (2008/9) & \multicolumn{2}{|l|}{$90.4 \%$} & $79.4 \%$ & {$[16]$} \\
\hline Percentage of skilled attendant births occurring in hospitals $(2008 / 9)^{1}$ & \multicolumn{2}{|l|}{$94.6 \%$} & $91.0 \%$ & \\
\hline Maternal mortality ratio (period) & \multicolumn{2}{|c|}{$335 / 100,000(2000-5)$} & $769 / 100,000(2000-7)$ & {$[17,18]$} \\
\hline Antenatal HIV prevalence & $34.9 \%$ & & $39.9 \%$ & {$[16]$} \\
\hline \multicolumn{5}{|l|}{ Emergency Obstetric Care Signal Functions ${ }^{2}$} \\
\hline & Regional & District & District & \\
\hline Caesarian section rate (\%) & $12.0 \%$ & $14.0 \%$ & $19.0 \%$ & \\
\hline Forceps or vacuum equipment (for assisted vaginal delivery) & Available & Available & Available & \\
\hline Oxytocic drugs & Available & Available & Available & \\
\hline Anticonvulsants & Available & Available & Available & \\
\hline Blood transfusion & Available & Available & Available & \\
\hline
\end{tabular}

${ }^{1}$ Personal Communication. Candice Day. Using 2008/2009 DHIS data.

${ }^{2}$ Data collected in a quality of care inventory done during the research project, and routine data for three months collected at the time that the quality of care inventory was carried out.

In Hlabisa, while use appeared to be relatively equitable among the highest 4 quintiles, women in the lowest quintile were under-represented in the user group (Figure 2). As with Bushbuckridge, women in this quintile comprised only $8 \%$ of hospital users, despite having $20 \%$ of the need. The Partitions of Pearson's Chi-squared test also shows significant overall differences between need and use (p-value $<0.001)$ and further significant differences in dispersion across the SES distribution between need and use (p-value $<0.001$ ).

Access to maternal delivery services was explored through three interlinked dimensions: availability (e.g. proximity of the health facility to the population served), affordability (e.g. the association between the health service related costs and the ability of households to meet these costs) and acceptability (e.g. expectations of and providers' attitudes to patients and vice versa) [19]. Indicators of the access experience of women delivering in the hospitals, along these three dimensions are presented in Table 2 . These are also reported in greater detail elsewhere [20]. Differences in categorical variables between the two study sites are tested using a Chi-squared test of association, while differences in continuous variables between study sites are compared using the Wilcoxon Rank sum test. As expected, the vast majority of women required transport to reach the hospital, with mean travel times increasing to nearly two hours (109 minutes) in Hlabisa. Women in Hlabisa appeared to have better access to ambulance services, while in Bushbuckridge, more than half (53\%) had to hire a car to get to the hospital. When all health

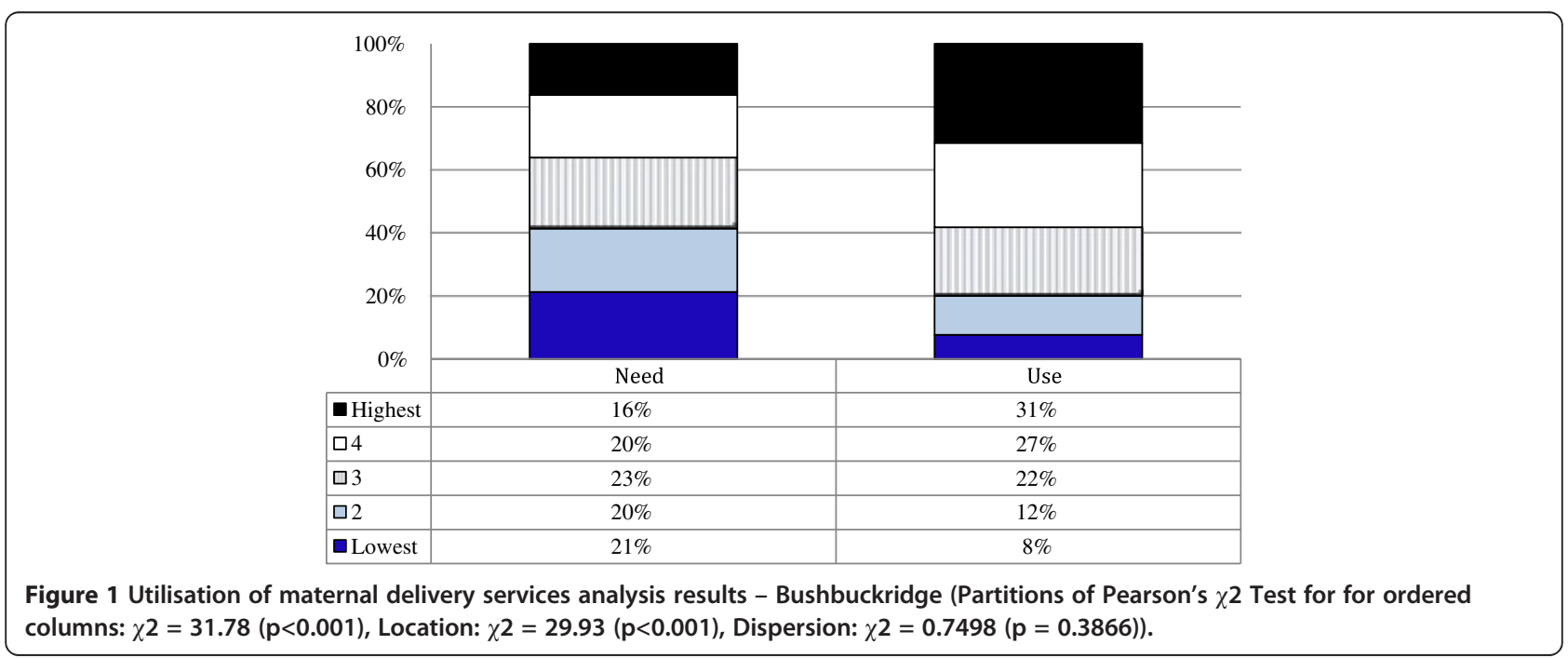




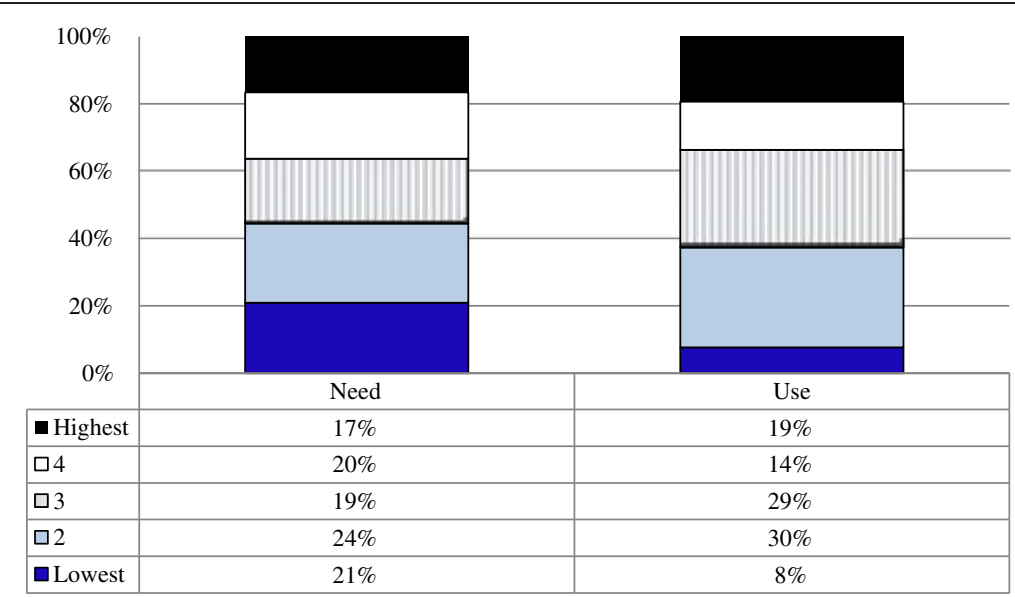

Figure 2 Utilisation of maternal delivery services analysis analysis results - Hlabisa (Partitions of Pearson's $\mathrm{X} 2$ Test for ordered columns: $\chi^{2}=105.4(p<0.001)$, Location: $\chi 2=0.09764(p=0.7564)$, Dispersion: $\chi 2=30.6(p<0.001)$ ).

expenses (transport, supplies, food, and childcare) were taken into account, the costs of the delivery (despite absence of user fees) constituted on average, half the monthly household expenditure in the two sites. One in seven women reportedly had to borrow money or sell assets in order to meet the costs of the delivery. One in four women in Bushbuckridge and nearly one in two women in Hlabisa felt that health workers were too busy to listen to their problems; one in three felt that health workers did not respect them.

\section{Discussion}

In two poor rural sub-districts in South Africa, those who are poor in relative terms compared to other members of the same community are most likely to belong to the small proportions of women who currently do not

Table 2 Experiences of access amongst women delivering in hospital

\begin{tabular}{|c|c|c|c|}
\hline & $\begin{array}{l}\text { Bushbuckridge } \\
(\mathrm{n}=299)\end{array}$ & $\begin{array}{l}\text { Hlabisa } \\
(n=300)\end{array}$ & $\begin{array}{l}\text { Statistic } \\
\text { p-value }\end{array}$ \\
\hline \multicolumn{4}{|l|}{ Availability } \\
\hline Transport to facility: & & & $\chi^{2}=143.600$ \\
\hline Foot & $12(4.0 \%)$ & $17(5.8 \%)$ & $p<0.000$ \\
\hline Bicycle & $1(0.3 \%)$ & $1(0.3 \%)$ & \\
\hline Taxi & $109(36.5 \%)$ & $95(32.5 \%)$ & \\
\hline Bus & $1(0.3 \%)$ & $7(2.4 \%)$ & \\
\hline Car & $157(52.5 \%)$ & $47(16.1 \%)$ & \\
\hline Ambulance & $19(6.4 \%)$ & $125(42.8 \%)$ & \\
\hline \multirow[t]{2}{*}{ Mean time to hospital (minutes) (95\% Cl) } & $48.4(43.8,53.0)$ & $109.6(98.4,120.9)$ & $z=10.997$ \\
\hline & & & $p<0.000$ \\
\hline \multicolumn{4}{|l|}{ Affordability } \\
\hline \multirow[t]{2}{*}{ Total costs of delivery as a percentage of household spending } & $51.4 \%$ & $49.7 \%$ & $z=-0.095$ \\
\hline & & & $p=0.9244$ \\
\hline \multirow[t]{2}{*}{ Number of households borrowing or selling assets to pay for health care } & $40(13.4 \%)$ & $44(14.7 \%)$ & $\chi^{2}=0.211$ \\
\hline & & & $p=0.6501$ \\
\hline \multicolumn{4}{|l|}{ Acceptability } \\
\hline \multirow[t]{2}{*}{ Health worker too busy to listen to my problems } & $65(25.6 \%)$ & $137(45.7 \%)$ & $\chi^{2}=23.931$ \\
\hline & & & $p<0.000$ \\
\hline \multirow[t]{2}{*}{ Health worker respects me } & $188(62.9 \%)$ & $197(65.9 \%)$ & $\chi^{2}=0.593$ \\
\hline & & & $p=0.4421$ \\
\hline
\end{tabular}


use hospital-based maternal delivery services. Inequalities in use of hospital based delivery services in these two rural sub-districts in South Africa confirm findings elsewhere [3] that access to delivery services is a particular problem for the poorest women within overall poor communities. We find that high proportions of women using hospitalbased maternal delivery services needed to borrow money or sell assets to fund this health care service, suggesting that affordability is a major barrier to care. In a context of free maternal health care at the point of use, low affordability relates principally to the costs of travelling to a hospital facility, especially during labour.

The policy relevance of these findings are that strategies that seek to improve utilisation may at present not sufficiently lower the barriers of cost and distance to maternal care for women in the lowest SES quintile. The emphasis on delivery in hospitals where emergency obstetric care is potentially available, even if not needed, may present insurmountable barriers for poor women. Although not examined in this study, it is possible that the differentials in use also relate to non-financial barriers, such as less respect or attention being shown by providers to poorer women. We can further not rule out that alternative preferences and attitudes towards hospital-based deliveries among the poorest women in the two subdistricts contributed to the access inequalities observed in our study.

In theory, it is possible to manage normal vaginal deliveries at primary care clinics, which are more accessible to the poorest women within the sub-districts. However, this delivery would clearly involve ensuring that clinics were equipped and staffed to handle basic obstetric care - as well as an investment in obstetric ambulances and defined and agreed referral criteria. These conditions are currently not met in the two sub-districts. Cleary et al. [21] performed a similar study on antiretroviral treatment in two urban sites in South Africa where treatment was provided at the clinic level, finding no significant difference between the SES distribution of HIV positive individuals (as a proxy for those needing ARVs) and a random sample of users of antiretroviral treatment. This result and our findings jointly suggest that the location of health care and geographical barriers are critical determinants of access.

Our study is the first to document local-level inequalities in use of maternal delivery services, even within two of the overall poorest districts in South Africa. The District Health Barometer's deprivation index, a measure of relative deprivation of populations across districts within South Africa, has placed Umkhanyakude District (containing Hlabisa) in the poorest $20 \%$ of districts and Ehlanzeni District (containing Bushbuckridge) in the second poorest $20 \%$ of districts in 2010/2011 [9]. However, the two districts display different patterns of inequality in access to hospital-based maternal delivery. This finding implies that policies to improve access among the poorest women in a district needs to be specific to the local context. For example, different patterns of transport use in the two districts studied, suggest that there is probably not a 'one size fits all' policy solution to this problem for all districts.

\section{Conclusion}

We find substantial socio-economic inequalities in use of hospital delivery services within two poor, rural districts in South Africa. Although the inequality patterns were different, in both sub-districts the women in the lowest quintile were least likely to use hospital-based delivery. Because the overwhelming majority of women in the sub-districts in this study do access hospital-based maternal delivery, these results suggest the need to shift the policy focus from ensuring overall access towards ensuring access particularly for the poorest women within the sub-districts.

\section{Abbreviations}

DHS: Demographic and Health Surveys; CEOC: Comprehensive emergency obstetric care; ANC: Antenatal care; MMR: Maternal mortality ratio; SES: Socio-Economic status; ARV: AntiRetroViral; MCH: Maternal and child Health; HDSS: Health and Demographic Surveillance System; REACH: Researching Equity in ACcess to Healthcare; AHDSS: Agincourt HDSS; ACDIS: Africa centre demographic information system; MCA: Multiple correspondence analysis.

\section{Competing interests}

The authors declare that they have no competing interests.

\section{Authors' contributions}

HS, SPS and LPK conceptualized the paper. SPS managed and analysed the data. SPS and LPK wrote the manuscript. TB and HS reviewed and provided extensive comments on the analytical methods and the manuscript. All authors read and approved the manuscript.

\section{Acknowledgements}

We are grateful to the MRC/Wits Rural Public Health and Heath Transitions Research Unit, School of Public Health, University of the Witwatersrand, for making available data from the Agincourt Health and Demographic Surveillance System for the Bushbuckridge sub-district analysis. Ms Candy Day of the Health Systems Trust kindly extracted data on profile of assisted deliveries in the two sub-districts. We are grateful to the entire REACH team (principal investigators, team members and collaborating sites): Di Mclntyre, Stephen Birch, John Eyles, Duane Blaauw, Bronwyn Harris, Pascalia Munyewende, Mosa Moshabela, Natsayi Chimbindi, Susan Cleary, Vanessa Daries, Veloshnee Govender, and Jana Fried for making this study possible.

\section{Funding}

This work was carried out with support from the Global Health Research Initiative (GHRI), a collaborative research funding partnership of the Canadian Institutes of Health Research, the Canadian International Development Agency, Health Canada, the International Development Research Centre, and the Public Health Agency of Canada.

\section{Author details}

${ }^{1}$ Department of Statistical Sciences, University of Cape Town, Cape Town, South Africa. ${ }^{2}$ Centre for Health Policy, School of Public Health, University of the Witwatersrand, Johannesburg, South Africa. ${ }^{3}$ Department of Global Health and Population, Harvard School of Public Health, Boston, USA. ${ }^{4}$ Wellcome Trust Africa Centre for Health and Population Studies, University of KwaZulu-Natal, Mtubatuba, South Africa. ${ }^{5}$ School of Public Health, University of the Western Cape, Cape Town, South Africa. 


\section{References}

1. Hosseinpoor AR, Victora CG, Bergen N, Barros AJ, Boerma T: Towards universal health coverage: the role of within-country wealth-related inequality in 28 countries in sub-Saharan Africa. Bull World Health Organ 2011, 89(12):881-890. Epub 2012/01/25.

2. Say L, Raine R: A systematic review of inequalities in the use of maternal health care in developing countries: examining the scale of the problem and the importance of context. Bull World Health Organ 2007 85(10):812-819. Epub 2007/11/27.

3. Barros AJ, Ronsmans C, Axelson H, Loaiza E, Bertoldi AD, França GV, Bryce J, Boerma JT, Victora CG: Equity in maternal, newborn, and child health interventions in Countdown to 2015: a retrospective review of survey data from 54 countries. Lancet 2012, 379(9822):1225-1233.

4. WHO: Commission on Information and Accountability for Women's and Children's Health: Keeping Promises, Measuring Results. Geneva: WHO; 2011.

5. Houweling TA, Ronsmans C, Campbell OM, Kunst AE: Huge poor-rich inequalities in maternity care: an international comparative study of maternity and child care in developing countries. Bull World Health Organ 2007, 85(10):745-754. Epub 2007/11/27.

6. Coovadia H, Jewkes R, Barron P, Sanders D, McIntyre D: The health and health system of South Africa: historical roots of current public health challenges. Lancet 2009, 374(9692):817-834. Epub 2009/08/28.

7. Blaauw D, Penn-Kekana L: Maternal Health. In South African Health Review 2010. Edited by Fonn S, Padarath A. Durban: Health Systems Trust; 2010:1.

8. Wabiri N, Chersich M, Zuma K, Blaauw D, Goudge J, Dwane N: Equity in Maternal health in South Africa: analysis of health service access and health status in a national household survey. PLoS One 2013, 8:9. e73864.

9. Day C, Barron P, Massyn N, Padarath A, English R: The District Health Barometer 2010/2011. Durban: Health Systems Trust (SA); 2011.

10. Data Collection: Overview of Data Collection procedures [Internet]. 2013. [cited 2013 June 24] Available from: http://www.agincourt.co.za/index.php/data/data-collection/.

11. Tanser F, Hosegood V, Barnighausen T, Herbst K, Nyirenda M, Muhwava W, Newell C, Viljoen J, Mutevedzi T, Newell M: Cohort Profile: Africa Centre Demographic Information System (ACDIS) and population-based HIV survey. Int J Epidemiol 2008, 37(5):956-962. Epub 2007/11/14.

12. Greenacre MJ, Blasius J (Eds): Correspondence analysis for the social sciences: Recent developments and applications. London: Academic Press; 1994.

13. Wolfe R: sg118: Partitions of Pearson's chi-square for analyzing two-way tables that have ordered columns. Stata Technical Bulletin 1999, 51:37-40.

14. WHO, UNFPA, UNICEF, AMDD: Monitoring emergency obstetric care. A handbook. Geneva: WHO; 2009

15. Statistics South Africa: Community Survey, 2007 Basic Results. Municipalities, Pretoria: Statistics South Africa (SA); 2008:109. Available from: http://www. statssa.gov.za/publications/p03011/p030112007.pdf.

16. Health Systems Trust: The District Health Barometer 2008/2009. Durban: Health Systems Trust (SA); 2009

17. Weiner R, Tollman S, Kahn K, Penn-Kekana L: Health and demographic surveillance sites contribute population-based data on maternal deaths in rural areas. S Afr Med J 2007, 97(10):944-945. Epub 2007/11/15.

18. Department of Health: Saving Mothers 2005-2007. The fourth report of the National Committee for Confidential Enquiry into Maternal Deaths in South Africa. Pretoria: Department of Health; 2009.

19. Mclntyre D, Thiede M, Birch S: Access as a policy-relevant concept in low- and middle-income countries. Health Econ Policy Law 2009, 4(Pt 2):179-193. Epub 2009/02/04.

20. Silal SP, Penn-Kekana L, Harris B, Birch S, Mclntyre D: Exploring inequalities in access to and use of maternal health services in South Africa. BMC Health Serv Res 2012, 12:120. Epub 2012/05/23.

21. Cleary S, Silal S, Birch S, Carrara H, Pillay-van Wyk V, Rehle T, Schneider H: Equity in the use of antiretroviral treatment in the public health care system in urban South Africa. Health Policy 2011, 99(3):261-266. Epub 2010/11/13.

doi:10.1186/s12992-014-0060-

Cite this article as: Silal et al: Local level inequalities in the use of hospital-based maternal delivery in rural South Africa. Globalization and Health 2014 10:60.

\section{Submit your next manuscript to BioMed Central and take full advantage of:}

- Convenient online submission

- Thorough peer review

- No space constraints or color figure charges

- Immediate publication on acceptance

- Inclusion in PubMed, CAS, Scopus and Google Scholar

- Research which is freely available for redistribution
C Biomed Central 